\title{
$\underline{\mathbf{P}-156}$
}

\section{Cytotoxicity Effect of Melastoma Malabatricum on Skin Melanoma and Cervical Cancer In Vitro}

\author{
Nurfariza Ahmad Roslen, Norafiza Zainuddin, Mohd Arifin Kaderi and Mohammad Syaiful Bahari \\ Abdull Rasad*
}

Department of Biomedical Science, Kulliyyah of Allied Health Sciences, International IslamicUniversity Malaysia, 25200

Kuantan, Pahang, Malaysia; E-mail: syaiful@iium.edu.my

Melastoma malabathricum is a local shrub, commonly known as senduduk that belongs to the family of Melastomataceae. The aim is to evaluate the potential anticancer activities of the different extracts from M. malabathricum. In this study, petroleum ether and chloroform were used in the extraction of stems and flowers of M. malabathricum. The extracts were tested for cytotoxic activity against skin melanoma cancer cell lines (A375) and cervical cancer cell lines (HeLa). Petroleum ether extracts of stem (PeMMS) showed significant growth inhibition of A375 cell lines, followed by the extract of flower (PeMMF). Meanwhile, PeMMF showed less significant growth inhibition of HeLa cell lines, followed by PeMMS. As for the chloroform extracts of stem (CHMMS) and flower (CHMMF), it does not inhibit the growth of both cell lines.

Keywords: Melastoma malabathricum, Petroleum ether extract, Chloroform extract, Anticancer. 